\title{
Aprender a democracia: Jovens e protesto no ensino secundário em Portugal
}

Learning democracy: Young people and protest in secondary education in

Portugal

Apprendre la démocratie : jeunes et contestations dans l'enseignement

secondaire au Portugal

\section{Ana Maria Seixas}

\section{CpenEdition}

\section{Journals}

Edição electrónica

URL: http://journals.openedition.org/rccs/988

DOI: $10.4000 /$ rccs. 988

ISSN: 2182-7435

\section{Editora}

Centro de Estudos Sociais da Universidade de Coimbra

Edição impressa

Data de publição: 1 Outubro 2005

Paginação: 187-209

ISSN: 0254-1106

Refêrencia eletrónica

Ana Maria Seixas, « Aprender a democracia: Jovens e protesto no ensino secundário em Portugal », Revista Crítica de Ciências Sociais [Online], 72 | 2005, colocado online no dia 01 outubro 2012, criado a 20 abril 2019. URL : http://journals.openedition.org/rccs/988 ; DOI : 10.4000/rccs.988 


\section{Aprender a democracia: Jovens e protesto no ensino secundário em Portugal}

A partir, fundamentalmente de relatos na imprensa e de entrevistas a alunos do ensino secundário, pretende-se, neste artigo, analisar as três principais mobilizações de protesto dos alunos do ensino secundário em Portugal desde os anos 90: a contestação à Prova Geral de Acesso ao Ensino Superior em 1992 e às Provas Globais em 1994, bem como o movimento contra a Política Educativa e Revisão Curricular no final da década de 90 e início da primeira década de 2000 . Procura-se compreender porque protestam os alunos do ensino secundário, quais os motivos e lógicas de justificação invocados, como se organizam e como vêem a sua participação, numa época em que a educação para a cidadania, visando a formação de cidadãos conscientes e participativos, é por demais salientada.

\section{Introdução}

Numa época em se enfatiza o afastamento dos cidadãos e sobretudo dos jovens das questões políticas, acusando-os de pouco interesse, envolvimento e participação na esfera política, os estudantes revelam, no entanto, capacidade de forte mobilização em momentos precisos. Pretende-se, neste artigo, analisar as três principais mobilizações de protesto dos alunos do ensino secundário em Portugal desde os anos 90: a contestação à Prova Geral de Acesso ao Ensino Superior em 1992 e às Provas Globais em 1994, bem como o movimento contra a Política Educativa e Revisão Curricular no final da década de 90 e início da primeira década de 2000.

Procura-se compreender porque protestam os alunos do ensino secundário, quais os motivos e lógicas de justificação invocados, como se organizam e como vêem a sua participação, numa época em que a educação para a cidadania, visando a formação de cidadãos conscientes e participativos, é por demais salientada.

Inicia-se este artigo com algumas notas teóricas sobre a participação política dos jovens, considerando o protesto como uma forma de participação política e salientando as novas características dos movimentos estu- 
dantis de protesto. São feitas, também, algumas referências às transformações sofridas nos campos dos ensinos secundário e superior português para uma melhor contextualização das acções colectivas de protesto dos alunos do ensino secundário. Procede-se, de seguida, à sua análise, descrevendo a história e salientando as especificidades das três mobilizações de protesto.

Utilizámos como fonte privilegiada no nosso estudo dois jornais diários nacionais, o Público e o Jornal de Notícias. Este artigo não pretende analisar, no entanto, a construção mediática das acções colectivas de protesto dos alunos do ensino secundário, embora se refira o papel dos media na construção social dos próprios movimentos de protesto. $\mathrm{O}$ recurso aos media para a análise dos movimentos e acções colectivas de protesto é defendido por vários autores (Koopmans e Rucht, 2002). Neste caso, face à ausência de outros documentos, os relatos de imprensa tornam-se fundamentais para a reconstituição da cronologia e da história das mobilizações de protesto.

Para uma melhor compreensão das lógicas e dinâmicas subjacentes ao último movimento de protesto, realizámos, durante o seu decurso, entrevistas a alunos de escolas secundárias da cidade de Coimbra. Privilegiámos a realização de entrevistas aos dirigentes associativos dinamizadores do Movimento das Associações de Estudantes do Ensino Secundário de Coimbra (MAEESC) durante o ano lectivo de 2002/3. Procurando apreender melhor a diversidade e a dissociação entre as lógicas das minorias activas e as lógicas das massas, entrevistámos também alunos sem um papel activo na coordenação e dinamização das acções de protesto. Embora tenhamos relatos de vários tipos de experiências escolares (Dubet, 1991), traduzindo uma certa diversidade do público estudantil, o carácter limitado e não representativo das entrevistas não nos permite generalizar as representações dos alunos. Julgamos, contudo, que estas constituem um contributo importante para a compreensão do protesto dos alunos do ensino secundário em Portugal.

\section{Jovens e protesto - uma nova forma de participação e consciência política?}

A ideia da falta de interesse dos jovens pela política, associada geralmente a uma crise de representação política e ao crescimento do grau de abstenção, parece estar profundamente arreigada nas nossas sociedades. Esta percepção está na base do renovado interesse pela temática da participação política dos jovens e da grande ênfase atribuída, a partir dos anos 90, à questão da educação para a cidadania, destacando-se a emergência de vários estudos 
de carácter comparativo apoiados por importantes organizações internacionais. ${ }^{1}$

Ao analisar as principais abordagens explicativas do aumento da não participação dos jovens britânicos nas eleições gerais, Richard Kimberlee (2002) considera as explicações assentes nas características dos jovens inadequadas para justificar a aparente fragilização da relação dos jovens com o voto. $\mathrm{O}$ autor critica, assim, o tipo de explicações, muito usual nos discursos dos media, que difundem a ideia de que os jovens sofrem de ignorância e de alienação, comparando quase invariavelmente de forma desfavorável a juventude de hoje com a geração de 60 . O autor contesta também o tipo de explicações centradas nas características das instituições e do sistema político e eleitoral, apesar de não refutar o fracasso dos partidos políticos em atrair os jovens. Este fracasso traduz-se, concretamente no caso britânico, numa diminuição da influência e representação dos jovens nos partidos tradicionais.

Um terceiro tipo de explicação, também não completamente satisfatório para o autor, assenta na ideia dos valores alternativos da juventude actual. Esta mudança geracional de valores, caracterizada segundo autores como Inglehart (1990) por uma "revolução silenciosa" em que os valores materialistas teriam dado lugar a valores pós-materialistas, explicaria a rejeição das formas tradicionais da política e a emergência de "uma nova política", reflectindo as preocupações e os valores das novas gerações.

Os novos movimentos sociais, vistos como resposta a um crescente desencanto com as formas tradicionais de política, contribuem para um aumento da politicização da sociedade e oferecem aos jovens uma oportunidade para o seu desenvolvimento pessoal e social.

Interrogando-se se de facto os jovens estarão realmente a rejeitar a política, Kimberlee enfatiza a necessidade de se ter em consideração as mudanças no processo de transição para o estatuto de adulto e, em particular, nas oportunidades de desenvolvimento da sua capacidade de participação política. De acordo com as explicações geracionais, o comportamento de cada geração é influenciado pelos acontecimentos sociais e políticos contemporâneos. A falta de envolvimento político dos jovens deverá ser vista, segundo Kimberlee, como um reflexo e como resposta às dificuldades que os jovens experimentam no processo de transição para o estado adulto,

\footnotetext{
${ }^{1}$ Veja-se, entre outros, o projectos IEA (International Association for the Evaluation of Education Achievement) Civic Education Study, que envolveu cerca de 140 mil jovens de vários países, entre os quais Portugal ( 90 mil estudantes de 14 anos em 28 países e 50 mil estudantes do ensino secundário em 16 países), e o estudo Citizenship Education at School in Europe realizado pela Eurydice/European Commission.
} 
processo esse, ele próprio, em profunda transição, dadas as importantes mudanças sociais em curso nas sociedades actuais. De acordo com Kimberlee, contrariamente às gerações anteriores, a única certeza para os jovens de hoje será a incerteza. A crescente preocupação com a educação para a cidadania reflectiria o facto de esta nova geração ter menos oportunidades para o desenvolvimento da sua própria identidade política, uma vez que parece gozar de uma menor probabilidade de experienciar em locais tradicionais como o trabalho, a família e a comunidade oportunidades para o seu envolvimento pessoal e social.

Também Anne Muxel (2002), ao estudar a participação política dos jovens franceses, refere a existência de um certo descrédito dos jovens, independentemente do seu capital escolar e origem social, relativamente à classe política e de uma certa rejeição das formas tradicionais de política, nomeadamente a participação em partidos políticos e em eleições. Referindo a importância do fenómeno Le Pen no processo de socialização política dos jovens franceses, Anne Muxel realça o contributo desta experiência geracional para o desenvolvimento da consciência e mobilização políticas dos jovens franceses. Embora se registe uma fractura intra-geracional, segundo o nível de instrução, nas atitudes e opções políticas dos jovens face ao caso Le Pen, é de salientar o reforço de uma forma de politização negativa, enfatizando um posicionamento político por defeito ou oposição mais do que por adesão ou convicção.

Ao analisar a evolução nas formas de participação política, Anne Muxel realça o aumento do protesto político nas gerações jovens com uma crescente participação dos jovens em manifestações colectivas de protesto. Para a autora, a prática da manifestação tornou-se uma experiência familiar para muitos jovens, que têm sido dos primeiros a sair para a rua em defesa da democracia e contra atentados aos direitos humanos, se bem que geralmente de forma mais ou menos espontânea e à margem das organizações políticas ou sindicais tradicionais. Muxel considera que é necessário ver nos usos diversificados, e por vezes contraditórios, do voto, da abstenção e da manifestação vias de aprofundamento da cultura democrática, traduzindo uma evolução nas formas de participação política, mais do que uma expressão de um défice democrático.

Segundo Isabel Menezes, para o caso português, os alunos do ensino secundário revelam bons conhecimentos sobre o funcionamento dos sistemas democráticos, valorizando, no entanto, ao nível da participação cívica mais as actividades de protecção ambiental do que a pertença a uma juventude partidária. Enquanto cerca de 6\% de uma amostra nacional de jovens de 14 anos e de jovens alunos do ensino secundário dizem participar numa 
organização de juventude partidária, 25\% afirmam participar numa organização ambiental e $8 \%$ numa organização de direitos humanos. A escola apresenta-se, contudo, como um local de excelência para o desenvolvimento de competências de participação cívica (Menezes, 2003; Amadeo et al., 2002).

Ao analisar os movimentos liceais franceses, François Dubet (1991) afirma que não existe um movimento liceal mas explosões escolares. Tal é atribuído ao facto da acção colectiva dos alunos não se centrar no estabelecimento escolar e na relação pedagógica mas sim no Estado, dado o carácter centralizado e burocrático da educação francesa, contribuindo, assim, para uma dissociação entre as minorias activas e as bases mobilizadas. A ausência de um movimento liceal derivaria, ainda, das próprias características da experiência escolar, salientando o autor a inexistência de um sentimento de pertença e de identificação do aluno ao liceu.

Ainda segundo este autor, os movimentos estudantis, a partir dos anos 80 seriam caracterizados por uma dissociação entre a crítica cultural, a luta política e a experiência escolar, em oposição aos dos anos 70 definidos pela crítica cultural e política. Os movimentos dos alunos parecem identificar-se cada vez menos com a crítica geral da sociedade ou da escola, não pondo em causa nem o seu funcionamento nem a sua finalidade, e os jovens aparecem cada vez mais afastados da política. Segundo Dubet, a acção colectiva dos alunos não se transforma em movimento colectivo organizado porque não valoriza as etapas da acção reivindicativa, da procura de participação e da crítica. Nas acções colectivas de protesto verifica-se mais uma justaposição das lógicas das minorias activas e das lógicas dos alunos em geral, do que uma verdadeira integração. $O$ fraco sentimento de pertença e de identificação dos alunos à sua escola é apresentado, também por Patrick Rayou (1998), como factor explicativo da não adesão às acções colectivas de protesto A desconfiança face à política e o receio de manipulação e de partidarização políticas do protesto explica porque as mobilizações estão distantes da lógica política.

Com uma perspectiva diferente, Alain Borredon (1995), critica a ideia de não comprometimento político dos jovens liceais. Para este autor, as acções colectivas de protesto dos alunos constituem uma forma política de comprometimento democrático e cívico ao reivindicarem um estatuto de actor social legítimo traduzido no direito à participação nas tomadas de decisão que os afectam (1995: 196).

Para além do contexto social onde emergem, uma análise dos movimentos de protesto dos alunos do ensino secundário implica ter em consideração desde logo a sua especificidade. Vistos como novos movimentos sociais, 
com uma certa (des)continuidade organizativa na dinâmica de mobilização e de adesão, os seus protagonistas são adolescentes (e não adultos), reivindicando e exercendo, nos movimentos de protesto, um estatuto de actor, quer na esfera política quer na esfera educativa (Borredon, 1996: 36). Outro factor de extrema importância na participação dos alunos em acções de protesto é o facto de estes estarem enquadrados numa instituição específica que condiciona fortemente a sua acção. Ou seja, a instituição escolar, os professores, e mesmo os grupos de colegas, através das suas práticas formais e informais, desde a justificação de faltas, a marcação ou adiamento de testes aos discursos de incentivo ou de reprovação, têm um papel importante no seu grau de envolvimento.

Segundo Borredon (1995: 169), para que o aluno se torne actor social é importante que a reivindicação comporte uma dimensão axiológica, seja impulsionada por líderes reconhecidos e implique um envolvimento de curta duração. Contrariamente aos movimentos estudantis das décadas de 60 e 70, as formas recentes de mobilização aparentam ser agora de curta duração, estando também associadas muitas vezes ao lúdico e à festa. A criatividade das formas de protesto torna-se fundamental não só para garantir a espectacularização da acção, e assim, a sua mediatização, como também para aumentar o grau de mobilização dos próprios alunos. Esta parece, também, depender mais da sua percepção enquanto vítimas ou destinatários de decisões políticas do que do seu nível de politização (Le Bart e Merle, 1997: 221). De acordo com Patrick Rayou, os jovens parecem aderir mais às manifestações para verificar a partilha de uma experiência de uma geração do que para obter resultados positivos. Ao manifestar-se publicamente, manifesta-se primeiro que tudo a si próprio a natureza dos seus sentimentos e a partilha a um grupo (1998: 167).

O grau de conhecimento dos alunos sobre as questões que originam os protestos parece variar conforme a proximidade do tema relativamente às suas preocupações imediatas e aos seus sistemas de valores. O conhecimento dos motivos, da causa, não é, no entanto, considerado fundamental, observando-se como que um efeito de delegação nos líderes, detentores de um maior grau de conhecimento das temáticas em discussão e com redes alargadas de acesso à informação (Borredon, 1996; Rayou, 1998). Esta confiança nos líderes traduz, de certo modo, as formas actuais e dominantes de democracia representativa. Se as acções de protesto dos jovens são caracterizadas por uma componente instrumental, elas apresentam, também, uma forte componente axiológica. Esta é principalmente visível nos líderes, cujo papel é fundamental nas mobilizações de protesto. 


\section{Mobilizações de protesto no ensino secundário em Portugal}

As mobilizações contra a Prova Geral de Acesso ao Ensino Superior em 1992, contra as Provas Globais em 1994 e contra a Política Educativa e Revisão Curricular no final da década de 90 e princípio da seguinte constituem as mais recentes e principais acções colectivas de carácter protestativo e reivindicativo dos alunos do ensino secundário em Portugal.

Estas três mobilizações, traduzindo um mal-estar e descontentamento, demonstram a capacidade de mobilização das gerações jovens actuais. Embora os alunos do ensino secundário se apresentem como os seus principais protagonistas, elas ocorrem em épocas de grande contestação à política educativa dos governos do momento, nomeadamente por parte dos estudantes do ensino superior. Desde os finais da década de 80 , com os governos de maioria social-democrata (1987-1995) que é visível a introdução de políticas neoliberais no campo do ensino superior em Portugal, de acordo com uma concepção mais economicista e empresarial do ensino. A explosão do sector privado de ensino superior, dada a incapacidade de resposta do sector público à crescente procura neste grau de ensino, e o desenvolvimento de políticas de recuperação de custos através do aumento substancial das propinas, traduzem de forma clara o desenvolvimento de processos de privatização, mercantilização e liberalização na educação.

No final dos anos 80, o sistema de ensino superior português iniciou uma nova fase no seu crescimento, caracterizada pela explosão dos seus efectivos. Entre 1990 e 1996, Portugal é o país membro da OCDE que regista a maior taxa de variação positiva de efectivos no ensino superior. Embora a evolução demográfica tenha contribuído para esta expansão, esta é fundamentalmente devida ao crescimento das taxas de frequência (OCDE, 1998: 197). As alterações introduzidas no regime de acesso ao ensino superior em Outubro de 1988, como a abolição do carácter eliminatório das provas de acesso, terão contribuído para esse crescimento. Este novo regime institui a Prova Geral de Acesso ao Ensino Superior. Esta prova tem como objectivo avaliar o desenvolvimento intelectual, o domínio da língua portuguesa e a maturidade cultural do candidato, não incidindo directamente sobre conteúdos curriculares específicos.

O número de candidatos ao ensino superior começa a decrescer a partir de 1995, encetando-se uma nova relação entre a oferta e a procura neste nível de ensino. Assim, enquanto no início dos anos 90 os candidatos ao ensino superior público representavam cerca do dobro dos lugares disponíveis no sector público, uma década depois regista-se uma paridade numérica entre ambos. 
O campo do ensino secundário conheceu também importantes mudanças nas últimas décadas. Com o aumento das taxas de escolarização verificou-se uma transformação do seu público estudantil com a chegada de novos alunos, que conforme salienta François Dubet (1991), se encontram na situação paradoxal de aceder ao ensino secundário no momento em que ele se desvaloriza. Este nível de ensino foi também objecto de importantes reformas curriculares desde os finais dos anos $80 .^{2} \mathrm{~A}$ reforma curricular no final da década de 80 surge no seguimento da nova Lei de Bases do Sistema Educativo de 1986, que instituiu o ensino básico obrigatório de 9 anos. Data desta altura a criação de novas áreas curriculares, Área-escola e Desenvolvimento Pessoal e Social, visando promover a formação cívica dos estudantes e a sua participação nas instituições democráticas, e a criação dos cursos tecnológicos nas escolas regulares e de cursos profissionais nas escolas profissionais no ensino secundário. É também no contexto desta reforma curricular que, em 1993, foram instituídas as Provas Globais, provas de avaliação final das disciplinas. Em 1995 o Partido Socialista ganhou as eleições gerais. Em 1997, o novo Ministro da Educação Marçal Grilo iniciou um novo processo de revisão curricular do ensino secundário, que foi aprovado em 2001 pelo XIV Governo, também socialista. Contudo, este processo foi suspenso em $2002 \mathrm{com}$ a entrada em funções do novo Governo PSD/CDS-PP. Este, por sua vez, apresentou uma nova proposta de reorganização curricular do ensino secundário, que foi aprovada em 2004. A reforma do ensino secundário, agora em curso, iniciou-se no ano lectivo de 2004/2005 com o $10^{\circ}$ ano, embora já no ano lectivo anterior tenham entrado em vigor alguns dos novos programas escolares.

\subsection{A luta contra a PGA - a capacidade crítica e de mobilização dos estudantes}

A 5 de Fevereiro de 1992, numa manifestação que durará todo o dia, mais de 500 alunos do ensino secundário de Barcelos marcham pela cidade, cortando o trânsito e reivindicando o fim da Prova Geral de Acesso ao Ensino Superior. Segundo a imprensa, são estes os primeiros a vir para a rua protestar, dois dias depois de realizadas as provas. A 7 de Fevereiro registam-se movimentos de protesto em várias cidades, destacando-se Coimbra, Braga e Lisboa, onde os alunos são recebidos no Ministério. O próprio júri da PGA admite "validade diminuta" nalgumas questões, não pondo, no entanto, em causa a validade da prova. Iniciado com acções espontâneas de protesto locais, o movimento contra a PGA alastra-se a todo o país e

\footnotetext{
${ }^{2}$ Ver Decretos-Lei n ${ }^{\circ} 286 / 89$ de 26/8, n ${ }^{\circ} 7 / 2001$ de 18/1 e n ${ }^{\circ} 74 / 2004$ de 26/3.
} 
durará cerca de um mês. A forte adesão dos alunos é visível pelo ritmo, intensidade e extensão espacial dos protestos. Durante as semanas seguintes registam-se mobilizações contra a PGA quase diariamente, em várias localidades do País.

O reportório de acção dos alunos vai desde a marcha ou manifestação de rua, a greves às aulas, a pedidos de audiências e entrega de abaixo-assinados, moções e cadernos reivindicativos a várias instituições (Câmaras Municipais, Governos Civis, Direcções Regionais de Educação, Ministério da Educação, grupos parlamentares da Assembleia da República), a conferências e comunicados à imprensa, ao corte de trânsito, ao corte de pontes, passando por formas de protesto de carácter mais simbólico e/ou lúdico como a queima de enunciado da PGA ou a simulação do seu enterro entoando a marcha fúnebre.

Os alunos começam por contestar o conteúdo da PGA, salientando a sua ambiguidade e subjectividade e os critérios aleatórios da classificação, acabando parte deles a exigir a sua extinção e a demissão do Ministro. A PGA é vista, nas palavras dos alunos, como "um totoloto", não havendo garantia de bons resultados escolares corresponderem a boas classificações na prova. As mobilizações contam desde o início com o apoio expresso de forma mais ou menos implícita dos próprios professores. ${ }^{3}$ Embora mantendo um forte carácter informal, os alunos procuram unir esforços, constituindo Comissões de Estudantes anti-PGA, criando Movimentos Não à $P G A$, elegendo delegações de representantes, tentando ultrapassar a pluralidade ideológica, não sem haver acusações de instrumentalização partidária da luta. Como resultado da sua coordenação, para além das manifestações locais, realizam-se manifestações de âmbito distrital e nacional. No dia da realização da $2^{a}$ chamada da PGA, a 17 de Fevereiro, 80 representantes de 36 escolas dos distritos de Lisboa e Setúbal decidem a composição da delegação a ser recebida pelo Ministro no dia da primeira manifestação nacional contra a PGA, a 20 de Fevereiro.

Perante 10000 alunos concentrados em Lisboa, a delegação será recebida pelo Ministro da Educação, tendo sido exortada a apresentar pareceres da não validade da prova. Cerca de mil alunos em Viana do Castelo bloqueiam

\footnotetext{
${ }^{3}$ Refira-se, por exemplo, o envio de uma carta pelos professores de português do Liceu Garcia da Orta, subscrita também por pais e alunos, ao Ministério da Educação, ainda durante a primeira semana de contestação, criticando a Prova Geral de Acesso: "Tratando-se de um teste que pretende avaliar, com objectividade, a maturidade e sentido crítico dos alunos que se propõem aceder ao ensino superior, não obedece ao rigor indispensável numa prova desta responsabilidade" (Jornal de Notícias, 16.2.1992).
} 
a passagem de uma ponte e sofrem uma carga policial, verificando-se também confrontos policiais noutras localidades. A 22 de Fevereiro é noticiada a constituição de uma Comissão de Acompanhamento da PGA, composta por representantes de alunos, pais, professores, universidades e Ministério da Educação.

A mobilização continuará, realizando-se nova greve nacional no dia 25, contando com o apoio da Confederação Nacional das Associações de Pais e de sindicatos de professores. Os alunos de Lisboa marcham pela cidade sendo recebidos pela Comissão Parlamentar da Educação, Ciência e Cultura da Assembleia da República, onde, segundo a imprensa, a JSD admitiu pedir a demissão do Ministro. A 1 de Março, cerca de 120 associações de estudantes do ensino secundário reúnem-se em Lisboa, onde são eleitos doze dirigentes associativos para comparecerem a uma reunião com o Ministro, prevista para o dia 5 de Março. A partidarização da luta torna visível as divisões entre os alunos. Cerca de 45 associações, mais próximas ideologicamente do governo, abandonam a sala como forma de protesto, aprovando as restantes 76 uma moção de rejeição da $3^{a}$ chamada e a anulação das provas. A delegação de alunos será recebida pelo Secretário de Estado do Sistema Educativo, a quem entregam pareceres técnicos e jurídicos contra a PGA. Este confirma a provável extinção da PGA, mas recusa a anulação das provas desse ano.

Durante o mês de Março é visível a diminuição da mobilização dos estudantes. O anúncio do provável fim da PGA e a demissão do Ministro Diamantino Durão são factores explicativos importantes. Realizar-se-iam ainda algumas manifestações contra a PGA, nomeadamente em Coimbra e Lisboa, sendo a desmobilização atribuída pelos dirigentes estudantis ao problema da justificação das faltas, à falta de informação, à afixação das classificações da $1^{\text {a }}$ chamada e ao próprio mau tempo. A imprensa fala sobretudo na crescente partidarização da luta.

Em Setembro de 1992 a PGA é abolida4. O slogan "assim acabámos com a PGA” será usado em manifestações seguintes dos estudantes do ensino superior, realçando a força e a importância do protesto.

A capacidade de mobilização e de adesão dos alunos está relacionada, como já foi referido, com vários factores. A identificação com os motivos do protesto parece ser fundamental. A questão do acesso ao ensino superior é de crucial importância para a definição da identidade pessoal dos jovens, uma vez que os resultados na PGA vão influenciar fortemente as suas trajectórias escolares, profissionais e sociais, ao condicionar o acesso ao ensino

\footnotetext{
${ }_{4}$ Ver Decreto-Lei n ${ }^{\circ}$ 189/92 de 3/9.
} 
superior e ao curso desejado. Os alunos começam por criticar os conteúdos, a forma de elaboração da prova e dos seus critérios de correcção, ${ }^{5}$ demonstrando um espírito crítico, contrariamente à ideia de uma aparente fraqueza dos estudantes em matéria de crítica escolar. "Propomos uma reformulação da PGA, exigimos provas que tenham utilidade e que sejam justas", provas que não sejam "ambíguas, selectivas, discriminatórias, elitistas e subjectivas" afirmam os alunos ${ }^{6}$, não pondo em causa a existência de provas de selecção de entrada no ensino superior.

É interessante verificar que uma contestação à ineficiência dos serviços do Ministério da Educação se vai transformar numa questão de justiça social, reivindicando os alunos o direito à igualdade de oportunidades. O carácter não escolar e arbitrário da prova, acentuando a questão das desigualdades sociais e da justiça social, põe em causa a ideologia meritocrática do acesso ao ensino superior. O sentimento comum de injustiça reforça a identidade colectiva da mobilização, contrapondo-se, de certa forma, a alguma heterogeneidade nas reivindicações, traduzindo divisões entre os jovens que se vão tornando mais visíveis ao longo do processo. ${ }^{7}$ Conforme refere E. Laraña (1999), a identidade colectiva é um elemento chave da unidade de acção e do potencial de mobilização do movimento. Ou seja, uma forte identidade colectiva parece ser fundamental para integrar a diversidade de orientações ideológicas e de interesses.

A informação tem também uma importância decisiva na extensão e difusão das mobilizações, conforme refere L Mathieu (2004). Um movimento com uma forte adesão implica sempre que os seus protagonistas possam verificar que outras unidades "do espaço de mobilização" também aderem. Ou seja, saber, neste caso, que outros alunos, outras escolas, também estão na luta incita à participação, uma vez que reforça a ideia de que não serão os únicos e que a mobilização poderá ser eficaz. Os media terão tido aqui também um papel importante na construção do desenrolar do próprio movimento de protesto. A ampla difusão nos media das acções de protesto realizadas por todo o país terá contribuído de forma positiva para a mobilização dos alunos e da própria opinião pública. Se a ideia da inexperiência organizativa dos alunos é salientada pelos jornalistas, ao descreverem as

\footnotetext{
5 São criticadas principalmente as perguntas de analogias e as questões fechadas de selecção de palavras antónimas.

${ }_{6}^{6}$ Ver Público, 15.2.1992 e declaração de um estudante do Porto citado no Jornal de Notícias de 21 de Fevereiro de 1992.

7 Enquanto alguns estudantes eram a favor da abolição da PGA, outros, mais próximos da orientação ideológica do Governo, propõem apenas a sua reformulação e a possibilidade de realização de uma terceira chamada para os candidatos ao ensino superior desse ano.
} 
mobilizações realizadas durante o mês de Fevereiro ${ }^{8}$, tal aparece geralmente associado mais à espontaneidade dos protestos, traduzindo uma certa genuinidade dos mesmos, do que a uma certa imaturidade dos jovens.

A solidariedade e o apoio expresso dos professores, de várias personalidades políticas e dos partidos da oposição terão contribuído também para o potencial de mobilização dos jovens. Apesar da existência de alguns confrontos com populares no decorrer de certas acções protesto e de comportamentos mais excessivos por parte de alguns, também a opinião pública aparenta ser favorável aos protestos dos alunos.

Se os protestos contra a PGA constituem um bom exemplo da capacidade e força das mobilizações dos alunos, a contestação contra as Provas Globais na primavera de 1994 salienta, fundamentalmente, algumas das suas fragilidades.

\subsection{A "geração rasca"? As fragilidades das mobilizações de protesto}

A 5 de Maio de 1994, os alunos do ensino secundário manifestam-se na rua, por todo o país, contra as Provas Globais. No dia seguinte, Vicente Jorge Silva, num editorial do jornal Público, interroga-se se não estaremos "a assistir ao nascimento de uma geração rasca", criticando as manifestações de protesto pelo comportamento dos jovens, uma vez que aqueles terão transformado "os seus cortejos num desfile de palavrões, cartazes e gestos obscenos, piadas de caserna ou trocadilhos no mais decrépito estilo das velhas "repúblicas" coimbrãs" (Público, 6.5.1994). Para além da violência verbal, as manifestações ficarão também marcadas pela violência física, com os jovens a atirarem garrafas e pedras sobre a polícia e a vandalizarem automóveis. Embora os dirigentes atribuam alguns dos comportamentos mais violentos a grupos de agitadores, a imagem de uma juventude mal-criada e mal-educada marcará, a partir, daí, este movimento de protesto.

Integradas na nova reforma curricular do ensino secundário, as Provas Globais são instituídas em Outubro de $1993^{\circ}$, estando prevista a sua reali-

\footnotetext{
${ }^{8}$ No relato das manifestações no Porto do dia 25 de Fevereiro pode ler-se no Público (26.2.1992): "Uma manifestação espontânea e quase sempre desorganizada (...) Embora tenha havido um grupo de estudantes que após a $1^{\mathrm{a}}$ chamada de PGA se organizou e liderou o movimento contra a prova, o certo é que ontem foi a espontaneidade que acabou por comandar os jovens. Os percursos foram alterados várias vezes e a indecisão fez-se sentir com alguma frequência. Um dos polícias que seguia de moto à frente dos estudantes dizia: 'Isto assim não dá! É a anarquia total'”. Referindo-se também às manifestações dos estudantes, o jornalista Fernando Ferreira escrevia no Jornal de Notícias, "Os protestos têm surgido de forma tão espontânea que os próprios alunos não sabem como organizar as suas manifestações, como prevenir as autoridades quanto aos seus desfiles e como convocar uma conferência de imprensa (...) (JN, 26.2.1992).

9 Ver Despacho normativo 383/93 de 21 de Outubro.
} 
zação pela primeira vez, no final do ano lectivo de 1993/94, pelos alunos do $10^{\circ}$ ano. No entanto, só a 28 de Março é publicada a sua regulamentação.

A primeira acção contra as Provas Globais, reportada nos diários analisados, data de Janeiro. Alunos de Coimbra retêm funcionários na Direcção Regional de Educação durante uma hora, exigindo informações sobre as provas, enquanto meio milhar protesta na rua: "Ninguém nos informa, estamos a zero" (Público, 29.1.1994). O fim das provas globais será também reivindicado pelos alunos do ensino secundário a 24 de Março, em manifestações do Dia do Estudante realizadas em Lisboa e no Porto contra a reforma do sistema educativo.

Contudo, a mobilização geral de protesto às Provas Globais parece ter sido desencadeada por alunos da Escola Secundária de Esmoriz, que teriam começado a sensibilizar os colegas em Março, enviando cartas a cerca de 150 escolas, apelando à greve contra as provas globais e contra a reforma educativa. A 22 de Abril cerca de três mil alunos em Espinho contestam as provas, verificando-se também manifestações em inúmeras localidades do norte e centro do país.

Tal como tinha acontecido com o movimento de protesto contra a PGA, a contestação alastra-se a todo o país. Realizam-se novas acções em várias localidades ainda no final do mês de Abril, convocando os alunos uma manifestação nacional para o dia 5 de Maio. Depois da forte adesão a esta (mais de seis mil alunos em Lisboa, dez mil no Porto, dois mil em Faro, três mil em Coimbra), a desmobilização dos estudantes é cada vez maior, apesar dos esforços para manter a luta, apelando a novas acções de protesto locais, a manifestações e a greves nacionais (nos dias 11 e 30 de Maio e dia 7 de Junho) e ao boicote às provas. Como exemplo, diga-se que nas manifestações do dia 11 de Maio, pautadas pela contenção, participaram cerca de mil alunos em Lisboa e cerca de três mil no Porto. Os boicotes às provas, implicando o fecho a cadeado de algumas escolas, foram também escassos, e ocorreram fundamentalmente na área da grande Lisboa. ${ }^{10}$

Como aspecto potenciador da forte mobilização inicial contra as Provas Globais será de salientar a percepção existente quanto à importância e relevância das acções de protesto, dada a relativa vitória dos alunos do ensino secundário contra a PGA e a pressão dos estudantes do ensino superior face à questão das propinas, que terão contribuído para a demissão de dois Ministros da Educação, Diamantino Durão e Couto dos Santos.

${ }^{10}$ Segundo dados do Ministério, citados na imprensa, das 450 escolas onde se realizavam provas no dia 30 de Maio apenas ocorreram problemas em 20, das quais quatro não eram da área de Lisboa (Público, 31.5.1994). 
O forte clima de contestação ao Ministério da Educação, ${ }^{11}$ os apoios iniciais de sindicatos de professores, a própria posição do Conselho Nacional da Educação questionando os objectivos das provas, apareciam como factores favoráveis ao movimento de protesto.

As manifestações iniciais dos alunos podem ser vistas como um desejo de afirmação, traduzindo o seu descontentamento por uma sociedade onde o futuro parece cada vez mais incerto e que parece não os ter em consideração. ${ }^{12}$ Os alunos contestam a "indefinição em que a reforma os faz viver", o facto de serem "cobaias de um sistema deficiente e em experiências contínuas" ${ }^{13}$ e a forma tardia como foram informados do processo de avaliação. Como refere Lilian Mathieu, uma manifestação manifesta a existência de um grupo. Ao exprimir o seu protesto, exprime também a sua identidade dando-se publicamente a ver (2004: 139).

No entanto, desde o início, a mobilização de 1994 revela fragilidades importantes. Apesar de existir um consenso contra as provas, por estarem contra a lógica da avaliação da nova reforma, centrada no aluno e na avaliação contínua, o movimento caracteriza-se desde o seu início pelo dissenso, pela falta de um objecto único de contestação, traduzido na heterogeneidade das reivindicações. Tal deriva da própria natureza das provas, uma vez que a sua elaboração e calendarização é da responsabilidade de cada escola. Ou seja, se podemos referir a existência de um sentimento comum de injustiça partilhado pelos estudantes, tendo em conta o tratamento diferenciado das escolas relativamente à realização das provas,${ }^{14}$ como a sua calendarização, dispensa de aulas, matéria abrangida, grau de dificuldade, etc., o grau de indignação dos alunos é variável consoante a sua situação concreta.

É esta falta de consenso que justifica a descoordenação das acções de protesto, não existindo uma entidade coordenadora das associações de estudantes. Aliás, é interessante verificar que mesmo algumas associações se demarcam do processo porque não conseguem reunir consenso dentro da própria escola, particularmente quanto ao boicote às provas. Sob o lema

\footnotetext{
${ }^{11}$ Como exemplo, diga-se que na $1^{a}$ semana de Maio se registaram também manifestações dos estudantes do ensino superior (tendo estes sido alvo de uma carga policial), dos trabalhadores não-docentes e dos professores contra a política do Governo.

${ }_{12}$ A referência do Presidente do Governo Regional da Madeira Alberto João Jardim às manifestações dos estudantes, depois de contrariar a posição do seu Secretário Regional da Educação que anunciou a não realização de provas nesse ano na Madeira, como "uma contestação de menores" parece traduzir esta ideia de não reconhecimento (Público, 12.5.1994).

${ }_{13}$ Conforme comunicado da Comissão de alunos do $10^{\circ}$ ano da Escola Secundária Manuel Alegre de Espinho, citado no JN e Público, respectivamente, de 23.4.1994.

${ }^{14} \mathrm{~A}$ informação no início do mês de Abril de que as provas não seriam realizadas na Madeira, ao criar um sentimento de injustiça nos estudantes do continente, poderá também ter sido um forte potenciador da adesão inicial aos protestos.
} 
"ou todos, ou ninguém”, a impossibilidade de reunir consenso na própria escola, levou numas à realização das provas, e noutras, os anunciados boicotes ficaram, na hora da sua realização, pelas intenções, ou foram substituídos por acções simbólicas como a queima dos enunciados depois de feitas as provas.

Se a desmobilização verificada depois da manifestação nacional de 5 de Maio poderá ser explicada por uma maior pressão dos pais, dos professores e da opinião pública, que nitidamente deixa de ser favorável aos estudantes, parece-me apropriado recorrer aqui à clássica teoria da escolha racional para compreender a não adesão ao boicote. Para Mancur Olson (1998), o descontentamento não é suficiente para provocar o envolvimento do indivíduo numa acção de protesto. Os actores, numa lógica de custos/benefícios do seu potencial envolvimento, tendem a utilizar a estratégia do "free rider", na terminologia de Olson. Ou seja, manter-se-ão à margem da mobilização, deixando para os outros os riscos e esperando tirar algum proveito individual do seu sucesso. Ora, ao pensarem todos da mesma maneira, ninguém será mobilizado para a reivindicação. O receio da classificação de zero, numa prova que vale $25 \%$ da classificação final da disciplina, que, por sua vez, influenciará a nota de candidatura ao ensino superior, justifica a não adesão dos alunos ao boicote às provas.

As formas de acção utilizadas pelos alunos poderão, também, não ter sido as mais eficazes. Uma manifestação com pouca adesão pode ter efeitos desastrosos, pois é uma prova do pouco apoio à causa e, ao projectar uma imagem negativa do grupo, como foi o caso das manifestações de 5 de Maio, acaba por ser desqualificante para o movimento. A opção pelo boicote, na medida em que os interesses individuais entram em conflito com os interesses colectivos, estaria condenada a um certo fracasso. As crescentes divisões entre os estudantes, ${ }^{15}$ traduzindo uma certa partidarização da luta, terão também contribuído para uma contínua desmobilização.

A imagem que perpassou nos media das mobilizações dos alunos também não foi favorável. Com o título "Zero em comportamento", o Público salientava o contraste entre a excelente capacidade de mobilização e de entusiasmo dos estudantes com a forma como se manifestaram e a incapacidade de organização e de controlo por parte dos dirigentes. "Foi a muitos títulos lamentável a prestação que os alunos do secundário deram nas ruas de

\footnotetext{
${ }_{15}$ No Porto os alunos dividem-se em duas facções, a Federação das Associações de Estudantes do Ensino Secundário do Distrito do Porto e outra constituída por 17 Associações de Estudantes de Escolas do Ensino Secundário do Porto, Gaia, Valongo, Póvoa de Varzim, Viana do Castelo e Maia. As duas apresentam reivindicações diferentes, defendendo a primeira a realização das provas mediante certas condições.
} 
Lisboa (...) frases gritadas contra a ministra que esgotavam a cartilha do mais grosseiro e debochado calão" (Público, 6.5.1994). Para além da falta de comportamento cívico, os media enfatizam também a descoordenação das reivindicações ${ }^{16}$, o desconhecimento dos alunos de regras do processo de avaliação e a existência de erros ortográficos nos cartazes.

Classificado como fiasco pelos jornalistas (Público, 31.5.1994), o movimento de protesto contra as Provas Globais constituirá a primeira derrota clara dos estudantes, tendo também contribuído para uma mudança na opinião pública, agora muito menos sensível aos argumentos estudantis.

As mobilizações de 1994 podem ser vistas como uma explosão do descontentamento do mal-estar juvenil, numa sociedade que parece cada vez mais adiar, e mesmo nalguns casos negar, aos jovens um estatuto de actor social. Este problema do reconhecimento parece estar no centro do movimento de protesto iniciado no final dos anos 90.

\section{3. "A universidade é para nós, o secundário quer voz": a importância do reconhecimento e o papel dos líderes}

O movimento de protesto dos alunos do ensino secundário, desencadeado no final da década de 90 e início da seguinte, parece apresentar algumas particularidades face às anteriores mobilizações, tais como a sua forte dimensão axiológica, o carácter reivindicativo, a sua extensão e oscilação temporais, e o papel fundamental dos líderes.

Este movimento de protesto apresenta uma dimensão mais axiológica tendo como mote geral a defesa de um ensino público, de qualidade e universal, visando a construção de uma escola e sociedade melhores. A contestação não se centra, assim, numa única temática, mas engloba uma série de questões de política educativa, tais como a revisão curricular, nomeadamente algumas medidas de reorganização dos tempos lectivos (duração das aulas e dos períodos escolares) e dos cursos gerais e tecnológicos, a criação de um $13^{\circ}$ ano e a existência de provas globais; a educação sexual na escola; os numerus clausus; os recursos humanos e materiais das escolas e o estatuto do aluno.

Este movimento aparenta ser também mais reivindicativo do que os anteriores. Se os alunos protestam contra várias medidas a ser implementadas, eles exigem fundamentalmente o direito a participar, a ser reconhecidos

\footnotetext{
16 Veja-se a transcrição de declarações de alunos ao Público: «"Não estamos contra as provas, estamos contra as provas este ano, porque não tivemos tempo; só no terceiro período é que veio a circular a informar-nos. Não há tempo, não fazemos (...) mas (...) se fizermos, (Não digas isso pá, não fazemos e pronto!) não podem ser só 50 minutos. Em 50 minutos não se vê um ano: uma hora e meia é o ideal ('Tás maluco pá? Duas, pá! Duas!')” (Público, 19.5.1994)
} 
enquanto actores e cidadãos, ${ }^{17}$ e o direito a terem um ensino de qualidade, com condições materiais e humanas adequadas, além do cumprimento da legislação já existente, como por exemplo, no caso da educação sexual.

É esta componente axiológica e reivindicativa que explicará não só a extensão temporal do protesto, justificada também pela própria prorrogação do processo de revisão curricular, como as estratégias de organização e de mobilização desenvolvidas pelos dirigentes associativos, constituindo-se este, essencialmente como um movimento de líderes.

O movimento de protesto começa a ter uma certa visibilidade pública no início da Primavera de 2000, com manifestações levadas a cabo, primeiro por alunos de Coimbra, no Dia do Estudante, e depois do Porto e de Lisboa. A 11 de Maio, realizou-se uma manifestação nacional, com uma forte adesão (a imprensa fala de cinco a sete mil alunos em Lisboa e no Porto e em mais de dois mil em várias cidades do país), à qual se segue, no final desse mês, uma "semana de luto" nas escolas, caracterizada, pelo contrário, pela fraca mobilização. No entanto, estas acções resultam de um trabalho prévio de organização. Os alunos criam, ainda em 1999, estruturas organizativas, sem estatutos ou corpos dirigentes, de coordenação das suas acções de luta e de âmbito concelhio ou distrital. ${ }^{18}$ Estas estruturas organizativas informais irão constituir a Delegação Nacional de Associações de Estudantes do Ensino Secundário, onde serão discutidas e decididas as formas de luta a nível nacional. Estes dirigentes associativos não se revêem na única estrutura existente representante dos alunos do ensino secundário ${ }^{19}$, considerando-a instrumentalizada politicamente. Salientando a independência partidária destas novas estruturas, os dinamizadores deste movimento de protesto afirmam a existência de uma pluralidade de orientações ideológicas no seu seio, de acordo com as características das novas formas de acção colectiva e uma constante em mobilizações estudantis (Laraña, 1999).

As acções de protesto prolongar-se-iam por mais quatro anos, ao ritmo dos acontecimentos políticos e do ano escolar. De uma forma quase mimética, em finais de Novembro e início de Dezembro registaram-se manifes-

\footnotetext{
17 "Não queremos esclarecimentos, queremos a suspensão da revisão e participar na discussão", conforme afirma um dos dirigentes associativos, dinamizadores do MAEESC (Público, 15.2.2000).

${ }^{18}$ Destaque-se o Movimento das Associações de Estudantes do Ensino Secundário de Coimbra, a Plataforma de Associações de Estudantes do Ensino Secundário do Distrito do Porto e a Plataforma de Estudantes do Ensino Secundário do Distrito de Lisboa.

19 Referimo-nos à Confederação Nacional de Associações de Estudantes do Ensino Básico e Secundário, com representação no Conselho Nacional de Educação.
} 
tações locais de protesto em Coimbra, Porto e Grande Lisboa ${ }^{20}$, seguindo-se em Fevereiro um protesto nacional, e por último novas mobilizações na Primavera. Embora se verifiquem também alguns comportamentos mais violentos e registos de agressões policiais, as acções de protesto ficam, no geral, marcadas pela sua componente lúdica e de festa ${ }^{21}$, traduzindo a importância das dimensões expressivas e das emoções nos movimentos dos alunos (Dubet, 1991).

A forte mobilização nas acções de rua verificadas em 2000 e no ano lectivo seguinte foi-se esbatendo nos anos subsequentes. Na manifestação nacional de 21 de Fevereiro de 2002, a imprensa refere cerca de três mil alunos em Lisboa e mil e quinhentos no Porto. A participação é ainda menor na primeira manifestação nacional do ano lectivo seguinte, a 28 de Novembro, tendo ocorrido, no entanto, acções de protesto por todo o país.

A banalização das manifestações e a evolução dos próprios acontecimentos políticos, como a mudança de Governo e a suspensão da revisão curricular socialista, explicam em parte esta desmobilização dos jovens. Não sendo um movimento monotemático, e traduzindo o complexo jogo identitário que deriva destas acções de protesto, parece verificar-se, também, uma dissociação entre a identidade pública do movimento, construída essencialmente pelos media, e a sua identidade colectiva, o que não favorece a adesão e mobilização gerais. A ênfase na educação sexual, na eliminação dos numerus clausus ou na duração dos tempos lectivos, por exemplo, não só não traduz toda a dimensão axiológica do movimento, como acentua questões que muitos alunos não consideram fundamentais. É visível também uma dissociação entre as lógicas de acção das minorias activas e as dos alunos em geral.

Esta desmobilização revela as dificuldades, ou mesmo a impossibilidade, de se manter uma mobilização de longa duração neste tipo de movimento de protesto. A continuidade do movimento assenta fundamentalmente na consciência política dos seus dinamizadores. Dada a importância do seu papel, iremos privilegiar, de seguida, uma análise das suas representações, tendo como base entrevistas realizadas a seis membros do MAEESC no ano lectivo 2002/03, todos estudantes do $12^{\circ}$ ano.

\footnotetext{
${ }^{20}$ Com excepção do ano de 2002, onde as primeiras manifestações foram em Viseu e se registou uma manifestação nacional a 28 de Novembro.

21 "Partilhava-se cerveja, vinho, dançava-se capoeira e batucavam-se tambores" (Público, 4.4.2000) (...) O ambiente era mais de festa do que de outra coisa: ao ritmo dos mais que prováveis "djambés", malabaristas e cuspidores de fogo animavam as hostes, enquanto um grupo de raparigas fazia ondular no ar umas coloridíssimas fitas de tecido" (Público 22.2.02).
} 
Os dirigentes associativos apresentam-se como jovens dinâmicos e com uma grande consciencialização política, embora nem todos estejam enquadrados ou se reconheçam nos partidos políticos existentes. Todos eles têm uma experiência de participação em manifestações anteriores e nas associações de estudantes. Se o tornar-se dirigente associativo é atribuído fundamentalmente a características pessoais, como, por exemplo, o ser-se muito activo, dinâmico, sociável e solidário, a maioria torna-se "militante" na continuidade de práticas de interacção com os pares, sendo a influência da família de menor importância. Daí que a participação nas reuniões e nas tarefas dirigentes seja nuclear na produção de espaços privilegiados de convivialidade, de reflexão e de aprendizagem política, estruturando a definição das identidades pessoais e colectivas dos dirigentes.

O MAEESC, tendo como objectivo coordenar a acção de luta, é visto como um espaço privilegiado de discussão e de aprendizagem de uma democracia participativa, onde "todos são iguais" e onde a pluralidade de perspectivas é aceite. As tomadas de decisão assentes fundamentalmente na obtenção de consensos mais do que em votações é outra característica enfatizada pelos jovens dirigentes, acentuando a imagem do Movimento como um espaço de verdadeiro funcionamento democrático colegial. O carácter informal do Movimento, sem estatutos, presidente ou mesmo porta-voz, sem local nem datas definidas de reunião, é avaliado positivamente pelos seus membros, embora alguns tenham consciência que esta informalidade poderá dificultar a participação dos alunos não integrados nas redes de sociabilidade do grupo ou pôr em causa a legitimidade representativa do Movimento.

Reconhecendo, contudo, um maior destaque de alguns dos seus membros na coordenação e dinamização das acções de contestação, e mesmo na relação com os media, essa maior visibilidade é atribuída, sobretudo, à disponibilidade pessoal. É, também, esta maior disponibilidade que aparece como legitimadora da desigualdade sexual na participação no Movimento, registando-se uma maior participação masculina.

Estes jovens apresentam, no geral, uma imagem bastante positiva da escola no que respeita ao ambiente escolar, nomeadamente às relações entre alunos e entre estes e os professores. Eles têm também uma concepção muito instrumental da escola, considerando-a fundamental para o seu futuro, apresentando-se muito mais críticos e descontentes relativamente à sociedade. Embora tenham uma percepção de uma diminuição do apoio das escolas ao movimento de protesto, os Conselhos Executivos e os professores aparecem mais como aliados do que oponentes. Alguns alunos salientam, contudo, a atitude crítica e desencorajadora de alguns professo- 
res, ao referirem a "perda de tempo" e os possíveis reflexos negativos no aproveitamento escolar do envolvimento dos alunos, sobretudo dos líderes, nas acções de protesto.

Os dirigentes do Movimento revelam uma forte capacidade crítica e de auto-crítica das suas funções políticas de dinamização e regulação das formas de mobilização e de contestação. Avaliam, assim, de forma contundente as acções desencadeadas e as estratégias seguidas, bem como o papel dos media na sua projecção no espaço público.

Durante o ano lectivo de 2002/2003, os estudantes do ensino secundário de Coimbra realizaram três manifestações de rua, sendo a segunda integrada numa forma de protesto de carácter nacional. Estas acções colectivas de protesto caracterizaram-se por um decréscimo de participação. A crescente desmobilização dos alunos é atribuída fundamentalmente à saturação das acções de rua e à dificuldade crescente em aderir a estas acções à medida que se avança no ano escolar, devido ao problema da não justificação das faltas. Os jovens dirigentes questionam, contudo, as suas opções estratégicas. Se a primeira manifestação local é apontada como um exemplo de sucesso e de mobilização, dado o elevado número de alunos, mais de dois mil, que marcaram presença na rua, a sua eficácia é contestada, contudo, por alguns dos dirigentes estudantis. Muitos alunos teriam participado porque ao chegar à escola se teriam confrontado com os portões fechados. Impossibilitados de ir às aulas, acabariam por engrossar a manifestação mas sem grande consciência e conhecimento dos motivos do protesto. Tal acabou por ter um efeito contraprodutivo para o movimento. Por um lado, contribuiu para a difusão de uma imagem do jovem participante como ignorante e alienado, enfatizada, na opinião dos alunos, pelos media. Por outro, muitos destes alunos não participaram na segunda manifestação, devido também à proximidade temporal, optando alguns por fazer apenas greve às aulas não indo à escola. Esta diminuição da participação, tendo-se manifestado "apenas" cerca de quinhentos alunos, terá contribuído, por sua vez, para a transformação da terceira numa "manifestação de dirigentes associativos".

Embora critiquem a imagem negativa dos jovens que perpassa nos media, o grau de consciencialização política destes jovens dirigentes aparece em contraste com a imagem que têm dos seus colegas. A crescente desmobilização traduz também a dissociação entre as lógicas de acção dos jovens dirigentes e as lógicas de acção dos alunos em geral. A lógica política está presente sobretudo nos primeiros. Mesmo nestes é possível apreender lógicas diferentes conforme a sua experiência escolar. Enquanto alguns parecem privilegiar a crítica escolar, questionando sobretudo o carácter selectivo do 
sistema educativo, outros parecem centrar-se mais na crítica à sociedade, não pondo em causa o funcionamento da escola. Informar, consciencializar e mobilizar são consideradas tarefas principais das suas funções de dirigentes associativos. Estas tarefas são vistas, por um lado, como frustrantes, dada a sua dificuldade e a necessidade de praticamente recomeçar de novo a cada momento de luta, mas, por outro lado, como muito gratificantes, contribuindo de forma muito positiva para o seu crescimento pessoal e para a sua aprendizagem política, bem como para a dos seus colegas, pois permitem aumentar o seu grau de consciencialização política.

A alegria e o desejo de estar com os outros para avaliar decisões políticas sobre a escola ou decidir de acções a concretizar, lança os alicerces para uma participação cívica e cidadã mais aprofundada e reflectida por parte destes jovens, que não se conformam com o estado das coisas e querem fazer ouvir as suas vozes e alterar as escolas onde estudam e que sabem ser cruciais para o seu futuro profissional.

\section{Conclusão}

As três mobilizações de protesto dos alunos do ensino secundário abordadas traduzem a sua forte capacidade de mobilização, embora de curta duração. Se a componente instrumental é patente nas três mobilizações, os protestos têm subjacente também uma componente axiológica valorizando a questão da justiça social e da igualdade de oportunidades. A participação dos alunos nestas acções colectivas de protesto traduz uma nova forma de participação social, cívica e política, existindo no entanto lógicas de acção muito diferenciadas entre os alunos. O protesto é usado pelos alunos do ensino secundário como uma forma de exprimirem a sua existência e de terem voz.

As mobilizações de protesto traduzem o mal-estar e descontentamento dos jovens face a uma sociedade que lhes apresenta um futuro caracterizado pela instabilidade e a um sistema de ensino que reforça a incerteza ao estar em permanente mudança. A análise das acções colectivas de protesto dos alunos implica ter presente as características actuais da sociedade e do próprio sistema educativo. As importantes transformações socioeconómicas ocorridas nas últimas décadas, as diferenças nas próprias experiências escolares, dadas as mudanças nas estruturas curriculares, no recrutamento dos alunos e na valorização social e económica dos diplomas, impedem uma comparação destas acções com os movimentos estudantis das décadas de 60 e 70, que criticavam os valores tradicionais de uma sociedade caracterizada pelo crescimento económico e pelo pleno emprego. 
As mobilizações colectivas de protesto caracterizam-se pelo seu carácter deslocalizado não se centrando no estabelecimento de ensino, quer relativamente à causa, mesmo quando se reivindicam melhores condições nas escolas, quer relativamente aos adversários constituídos, neste caso, pelo governo ou Estado central. Mais do que a fraca integração ou identificação dos alunos ao seu estabelecimento de ensino, a concepção instrumental e a imagem positiva da sua escola, bem como o carácter deslocalizado dos motivos do protesto explicariam a dificuldade de uma mobilização de longa duração nestas acções.

O papel dos sentimentos e das emoções parece ser de crucial importância nas acções colectivas de protesto. Mais do que os motivos ou a eficácia da acção, é determinante na participação dos alunos o facto de a manifestação aparecer como um espaço de afirmação de sentimentos e da identidade pessoal e social, ao permitir a partilha de uma experiência comum. Daí a importância do carácter festivo das acções, vistas como espaços de convivialidade. A participação em acções colectivas de protesto justificada pela solidariedade revela também o papel da emoção. Tal acontece quando os alunos protestam não porque a sua situação ou a do seu estabelecimento seja má, mas porque o sistema , outras escolas, outros alunos têm problemas.

A constituição de estruturas organizativas informais de coordenação das acções colectivas de protesto traduz o receio da manipulação e partidarização da luta e a desconfiança que os jovens aparentam ter face às formas tradicionais de política, bem como às formas institucionais de participação na instituição escolar. Este receio é expresso pelos próprios líderes ao salientarem a independência partidária e a pluralidade ideológica destas estruturas. O seu carácter pouco institucionalizado estaria de acordo com o espírito de autonomia e de independência que os jovens enfatizam, embora possa pôr em causa a legitimidade da representatividade das acções colectivas de protesto. Se os alunos reivindicam um reconhecimento enquanto actores sociais, eles parecem ter consciência das suas limitações e recusam-se a assumir um estatuto que não é o deles.

O carácter pouco formalizado das mobilizações de protesto dificulta tambem a avaliação dos seus progressos ou resultados. Contudo o que nos parece importante de salientar é o facto destas acções colectivas traduzirem um processo de aprendizagem colectiva e de desenvolvimento de uma consciência política e participativa nos alunos do ensino secundário. Elas permitem desenvolver nos alunos competências pessoais e sociais essenciais para a sua acção política, contribuindo para a formação de cidadãos participativos numa sociedade democrática e mais justa. 


\section{Referências Bibliográficas}

Amadeo, Jo-Ann et al. (2002), Civic Knowledge and Engagement. An IEA Study of Upper Secondary Students in Sixteen Countries. Amsterdam: International Association for the Evaluation of Educational Achievement.

Borredon, Alain (1995), Une jeunesse dans la crise. Les nouveaux acteurs lycéens. Paris: L'Harmattan.

Borredon, Alain (1996), "Les nouveaux acteurs lycéens: critique social et critique scolaire", Revue Française de Pedagogie, 116, 33-42.

Dubet, François (1991), Les Lycéens. Paris: Seuil.

Eurydice (2005), Citizenship Education at School in Europe. Brussels: Eurydice European Unit.

Inglehart, Ronald (1990), Cultural Shift in Advanced Industrial Society. Princeton: Princeton University Press.

Kimberlee, Richard (2002), “Why Don't British Young People Vote at General Elections?", Journal of Youth Studies, 5(1), 85-98.

Koopmans, Ruud; Rucht, Dieter (2002), "Protest Event Analysis", in Bert Klandermans; Suzanne Staggenborg, Methods of Social Movement Research. Minneapolis: University of Minnesota Press, 231-259.

Laraña, Enrique (1999), La construcción de los movimientos sociales. Madrid: Alianza Editorial.

Le Bart, Christian; Merle, Pierre (1997), La citoyenneté étudiante. Intégration, participation, mobilisation. Paris: PUF.

Mathieu, Lilian (2004), Comment lutter? Sociologie et movements sociaux. Paris: Textuel.

Menezes, Isabel (2003), "Participation Experiences and Civic Concepts, Attitudes and Engagement Implications for Citizenship Education Projects”, European Educational Research Journal, 2(3), 430-445.

Muxel, Anne (2002), "La participation politique des jeunes: sobresauts, fractures et ajustements”, Revue Française de Sciences Politiques, 52(5-6), 521-544.

OCDE (1998), Regards sur l'éducation. Les indicateurs de l'OCDE. Paris: OCDE.

Olson, Mancur (1998), A lógica da acção colectiva: Bens públicos e teoria dos grupos. Oeiras: Celta Editora.

Rayou, Patrick (1998), La Cité des lycéens. Paris: L'Harmattan. 